\title{
Protective Effect of Serum Thymic Factor, FTS, on Cephaloridine-Induced Nephrotoxicity in Rats
}

\author{
Yuka Kohda, ${ }^{* a}{ }^{, a}$ Yoshiko Matsunaga,${ }^{a}$ Katsuya Yonogi,${ }^{a}$ Yoshiko Kawai, ${ }^{a}$ Akira Awaya, ${ }^{b}$ and \\ Munekazu GemBA ${ }^{a}$ \\ ${ }^{a}$ Division of Pharmacology, Osaka University of Pharmaceutical Sciences; Nasahara, Takatsuki, Osaka 569-1094, Japan: \\ and ${ }^{b}$ Japan Science and Technology; Tachikawa, Tokyo 190-0012, Japan. \\ Received May 12, 2005; accepted August 2, 2005
}

Serum thymic factor (FTS), a thymic peptide hormone, has been reported to increase superoxide disumutase (SOD) levels in senescence-accelerated mice. In the present study, we examined the effect of FTS on cephaloridine (CER)-induced nephrotoxicity in vivo and in vitro. We previously reported that CER led to extracellular signal-regulated protein kinase (ERK) activation in the rat kidney. So, we also investigated whether FTS has an effect on ERK activation induced by CER. Treatment of male Sprague-Dawley rats with intravenous CER $(1.2 \mathrm{~g} / \mathrm{kg})$ for $24 \mathrm{~h}$ markedly increased BUN and plasma creatinine levels and urinary excretion of glucose and protein, decreased creatinine clearance and also led to marked pathological changes in the proximal tubules, as revealed by electron micrographs. An increase in phosphorylated ERK (pERK) was detected in the nuclear fraction prepared from the rat kidney cortex $24 \mathrm{~h}$ after CER injection. Pretreatment of rats with FTS (50 $\mu \mathrm{g} / \mathrm{kg}$, i.v.) attenuated the CER-induced renal dysfunction and pathological damage. FTS also suppressed CER-induced ERK activation in the kidney. In vitro treatment of the established cell line, LLC-PK 1 cells, with FTS significantly ameliorated CER-induced cell injury, as measured by lactate dehydrogenase (LDH) leakage. Our results, taken together with our previous report that MEK inhibitors ameliorated CER-induced renal cell injury and ERK activation induced by CER, suggest that FTS participates in protection from CER-induced nephrotoxicity by suppressing ERK activation induced by CER.

Key words cephaloridine; nephrotoxicity; serum thymic factor (FTS); extracellular signal-regulated protein kinase (ERK) activation; renal cell injury

Cephaloridine (CER), a cephalosporin antibiotic, has been proven to be nephrotoxic, and has been reported to induce acute renal failure as a side effect in both experimental animals and humans. ${ }^{1-3)}$ Experimental animals injected with CER undergo renal damage characterized by acute proximal tubular necrosis, most prominently of the S2 segment of the tubules, ${ }^{4)}$ where CER is transported by the renal basolateral transport system for organic anions from the blood to the proximal tubular cells. ${ }^{5)}$ However, CER is limited in its movement to the tubular lumen, resulting in its high accumulation within the proximal tubular cells, which are critical for promoting the development and progression of renal disease. ${ }^{6-8)}$

Serum thymic factor (FTS) is a nonapeptide thymic hormone which was first isolated from pig serum by Bach et al. and then from the thymus. ${ }^{9)}$ FTS is secreted by thymic epithelial cells and is involved in functional activation and differentiation in $\mathrm{T}$ cells. ${ }^{10,11)}$ In addition to its action as a thymic hormone, FTS exerts a variety of biological activities both in vivo and in vitro, including an immunobiological effect. $^{12-15)}$ Previous reports have shown that FTS prevents experimental pancreatitis and diabetes induced by alloxan or streptozotocin, and diabetes and myocarditis caused by the encephalomyocarditis virus in mice. ${ }^{16,17)}$ Other studies have reported that FTS also suppresses acute experimental allergic encephalomyelitis and skin fibrosis during wound repair. ${ }^{18,19)}$

CER nephrotoxicity is due in part to the generation of reactive oxygen species (ROS), and the ROS-induced peroxidation of cell membrane lipids is the most likely mechanism of renal injury caused by CER. ${ }^{20-23)}$ Recently, ROS have been demonstrated to modulate signaling pathways in cellular responses. ${ }^{24)}$ The mitogen-activated protein kinase
(MAPK) family are important mediators of signal transduction processes that serve to coordinate cellular responses to a variety of extracellular stimuli. Mammals express at least four distinctly regulated groups of MAPKs, the extracellular signal-regulated protein kinase (ERK) 1/2, c-Jun N-terminal kinase (JNK), p38 MAP kinase and ERK5 cascades are each capable of responding to different stimuli, such as cellular stress and growth factors. ${ }^{25)}$ The most well characterized of these is the ERK pathway. Numerous studies have demonstrated that the ERK pathway is mainly activated by a variety of growth factors and known to be associated with cellular proliferation and differentiation. ${ }^{26,27)}$ Several in vivo studies have shown that the ERK cascade is phosphorylated in the damaged brain caused by ischemia and hypoglycemia. ${ }^{28,29)}$ The biological outcome of MAPK activation may be attributed to difference in cell types.

We and others have previously demonstrated that ROS mediate CER-induced renal damage. ${ }^{20-23,30,31)}$ A previous report has shown that FTS increases superoxide disumutase (SOD) levels in senescence-accelerated mice. ${ }^{32)}$ It has also been reported that bleomycin-induced pulmonary injury can be prevented by the administration of FTS. ${ }^{33)}$ Thus, we hypothesize that FTS, having a variety of biological activities, might modify cell damage and tissue injury, and possibly attenuate free radical-mediated renal cell injury and nephrotoxicity caused by CER. We have previously reported that an MEK/ERK pathway is probably concerned in free radical-induced injury in rat renal cortical slices. ${ }^{34)}$ In the present study, we investigated our hypothesis whether FTS prevents the development of CER-induced nephrotoxicity in vivo and in vitro. The aim of this study was also to examine the effect of FTS on CER-induced ERK activation in the rat kidney. 


\section{MATERIALS AND METHODS}

Chemicals CER was supplied from Shionogi \& Co. Ltd. (Osaka, Japan). FTS was supplied from Carlbiotech (Copenhagen, Denmark). Dulbecco's Modified Eagle Medium (D-MEM) and nutrient medium F-12 (1:1) were purchased from Invitrogen Co. (Carlsbad, CA, U.S.A.). Fetal bovine serum was obtained from Trace Scientific Ltd. (Melbourne, Australia). The anti-phospho MAP kinase (pERK) antibody was purchased from the Sigma Chemical Co. (St. Louis, MO, U.S.A.). An antibody specific to ERK was from BD Transduction Laboratories (Lexington, KY, U.S.A.). Secondary anti-mouse $\operatorname{IgG}(\mathrm{H} \& \mathrm{~L}$, horseradish peroxidaselinked) was from Amersham Pharmacia Biotech, (NJ, U.S.A.). Protease inhibitor was purchased from Nacalai Tesque, Inc. (Kyoto, Japan). All other chemicals used were of the highest purity available (Wako Pure Chemical Industries, Ltd., Osaka, Japan).

Cell Culture LLC-PK $_{1}$ cells, a cultured renal epithelial cell line derived from the porcine kidney, were obtained from the American Type Culture Collection (Rockville, MD, U.S.A.). The cells were cultured in Dulbecco's Modified Eagle's Medium containing nutrient mixture F-12 (D-MEM/F12) supplemented with $5 \%$ fetal bovine serum (FBS) in a humidified atmosphere of $95 \%$ air and $5 \% \mathrm{CO}_{2}$ at $37^{\circ} \mathrm{C}$. To obtain confluent cells, the cells were fed fresh medium without FBS on the fourth day after being seeded. CER was added to the fresh medium $2 \mathrm{~h}$ after medium exchanges. LLC-PK cells were treated with various concentrations of FTS $1 \mathrm{~h}$ before exposure to $5 \mathrm{~mm}$ CER for $24 \mathrm{~h}$, and lactate dehydrogenase (LDH) leakage was determined after incubation for $24 \mathrm{~h}$.

Determination of Cell Injury The index of renal cell injury was LDH leakage from the cells into the media. At the end of incubation, the medium was collected for determination of LDH activity. The cells were harvested and suspended in $1 \%$ Triton X-100 solution and then sonicated before use. LDH activity in the medium and the cells was determined using a commercial kit (Wako Pure Chemical Industries, Ltd., Osaka, Japan).

CER-Induced Nephrotoxicity in Rats Experiments were performed on Male Sprague-Dawley rats (6-7 weeksold; Japan SLC, Inc., Shizuoka) to develop CER-induced acute renal failure. The animals were allowed free access to tap water and a standard laboratory diet. The animals were given intravenous injections of CER dissolved in isotonic saline $(1.2 \mathrm{~g} / \mathrm{kg})$, and were treated with FTS $(50 \mu \mathrm{g} / \mathrm{kg}$, i.v. $)$ 24 and $18 \mathrm{~h}$ before CER injection. Control animals received injections of an equal volume of vehicle (isotonic saline solution). The animals were anesthetized with sodium pentobarbital $(50 \mathrm{mg} / \mathrm{kg}$, i.p.) $24 \mathrm{~h}$ after CER injections and their kidneys were removed first, and then blood samples were drawn from the abdomen aorta. These samples were used to measure plasma creatinine and blood urea nitrogen (BUN) levels by a colorimetric method using a spectrophotometer. Urine was collected after CER treatment by placing the rats in metabolic cages for $18 \mathrm{~h}$. Urine samples were collected into bottles on ice. These samples were used to measure urine creatinine, glucose and protein levels by a colorimetric method using a spectrophotometer. Creatinine clearance (Ccr) was calculated as follows:
$\mathrm{Ccr}(\mathrm{ml} / \mathrm{h})=[$ urinary creatinine $(\mathrm{mg} / \mathrm{dl}) \times$ urinary volume $(\mathrm{ml} / \mathrm{h})] /[$ plasma creatinine $(\mathrm{mg} / \mathrm{dl})]$

Electron Microscopy Transverse sections of the kidney cortex were minced into $1 \mathrm{~mm}^{3}$ cubes $24 \mathrm{~h}$ after treatment with CER and/or FTS. For electron microscopy, the sections were fixed in $2.5 \%$ glutaraldehyde and $1 \%$ formaldehyde in $0.1 \mathrm{~m}$ PBS (pH 7.4), and refrigerated for up to $24 \mathrm{~h}$. Samples were postfixed in $1 \%$ osmium tetroxide in $0.1 \mathrm{~m}$ phosphate buffer, dehydrated through a graded series of ethanol and propylene oxide, and then embedded in epoxy resin. Semithin sections approximately $1 \mu \mathrm{m}$ thick were cut with glass knives and stained with toluidine blue. After areas of interest were identified, ultrathin sections were cut with diamond knives and stained with $1 \%$ uranyl acetate for $20 \mathrm{~min}$ and $1 \%$ lead citrate for $2 \mathrm{~min}$. Electron microscopic findings were obtained, and photographed using a HITACHI H-600 transmission electron microscope.

Preparation of the Nuclear Fraction Nuclear fractions were prepared from the kidney cortex of rats treated with CER and/or FTS by a modification of the method of Dignam et $a l .{ }^{35)}$ Kidneys were rapidly placed in ice-cold hypotonic buffer, which consisted of $10 \mathrm{~mm}$ HEPES (pH 7.6), $15 \mathrm{~mm}$ $\mathrm{KCl}, 2 \mathrm{~mm} \mathrm{MgCl}_{2}, 0.1 \mathrm{~mm}$ EDTA, $1 \mathrm{~mm}$ dithiothreitol, and $0.2 \%$ Nonidet P-40 with protease inhibitors (1 mM phenylmethylsulfonyl fluoride, $1 \mu \mathrm{g} / \mathrm{ml}$ aprotinin, $1 \mu \mathrm{g} / \mathrm{ml}$ leupeptin, and $1 \mu \mathrm{g} / \mathrm{ml}$ pepstatin) to prevent proteolysis and $/$ or dephosphorylation. The kidneys were homogenized at $0{ }^{\circ} \mathrm{C}$ in a glass homogenizer and centrifuged at $850 \times \boldsymbol{g}$ for $10 \mathrm{~min}$ at $4{ }^{\circ} \mathrm{C}$. The resultant pellets were suspended in hypotonic buffer, and recentrifuged at $850 \times \boldsymbol{g}$ for $10 \mathrm{~min}$ at $4^{\circ} \mathrm{C}$. The nuclear pellet was disrupted in hypertonic buffer, which consisted of $25 \mathrm{~mm}$ HEPES (pH 8.0), $50 \mathrm{~mm} \mathrm{KCl}, 0.1 \mathrm{~mm}$ EDTA, $1 \mathrm{~mm}$ dithiothreitol, $10 \%$ glycerol, $0.4 \mathrm{M} \mathrm{NaCl}$ and protease inhibitors, for $30 \mathrm{~min}$ on ice for use as the nuclear fraction and recentrifuged at $18000 \times \boldsymbol{g}$ for $15 \mathrm{~min}$ at $4{ }^{\circ} \mathrm{C}$. Its supernatant was used as the soluble nuclear fraction and for western blot analysis. The PIERCE protein estimation kit was used to determine the protein concentration with bovine serum albumin as the standard.

Electrophoresis and Western Blot Analysis Equal amounts of the soluble nuclear protein (10 $\mu \mathrm{g}$ protein) in the above fraction were separated by $10 \%$ SDS-polyacrylamide gel electrophoresis (SDS-PAGE). The proteins were transferred to nitrocellulose membranes using a semi-dry blotting system. The membranes were blocked with $3 \%$ bovine serum albumin (BSA) or 5\% skimmed milk in buffer containing $50 \mathrm{~mm}$ Tris- $\mathrm{HCl}$ (pH 7.5), $150 \mathrm{~mm} \mathrm{NaCl}$ and $0.1 \%$ Tween 20 (TBST) overnight at $4{ }^{\circ} \mathrm{C}$, and then incubated with the primary antibody specific against phospho-ERK (pERK) and ERK in $1 \%$ BSA-TBST or $2 \%$ skimmed milk for $30 \mathrm{~min}$ at $37^{\circ} \mathrm{C}$. The membranes were washed three times in TBST to remove unbound antibodies and then incubated with a horseradish peroxidase-conjugated secondary antibody in $1 \%$ TBST for $30 \mathrm{~min}$ at $37^{\circ} \mathrm{C}$. Enhanced chemiluminescence (ECL) Western blotting detection reagents (Amersham Pharmacia Biotech, NJ, U.S.A.) were used to detect the immunoreactive bands of pERK and ERK.

Statistical Analysis All values are expressed as means \pm S.E.M. All data were evaluated by one-way analysis of variance and Scheffe's tests for multiple comparisons of 
means. ${ }^{36)} p$ values less than 0.05 were considered significant.

\section{RESULTS}

Effect of FTS on CER-Induced LLC-PK 1 Cell Injury To investigate whether FTS prevents CER-induced cell injury, LDH leakage was examined as an index of renal cell injury. LLC-PK 1 cells were treated with CER at a concentration of $5 \mathrm{~mm}$ for $24 \mathrm{~h}$. CER significantly increased LDH leakage from the cells after $24 \mathrm{~h}$ of exposure. FTS at 0.1 and $10 \mathrm{~nm}$ ameliorated the CER-induced increase in LDH leakage (Fig. 1).

Induction of Acute Renal Failure by CER Administration Acute renal failure was successfully induced $24 \mathrm{~h}$ after CER (1.2 g/kg, i.v.) administration. BUN levels were significantly higher in CER-administered rats $(56.8 \pm 3.1 \mathrm{mg} / \mathrm{dl})$ compared with normal controls $(18.1 \pm 1.9 \mathrm{mg} / \mathrm{dl})$ (Table 1). Plasma levels of creatinine were also higher in CER-administered rats $(1.27 \pm 0.13 \mathrm{mg} / \mathrm{dl})$ than in normal controls $(0.40 \pm 0.05 \mathrm{mg} / \mathrm{dl})$ (Table 1). Compared with those in the saline-treated control group, rats in the CER-treated group showed significant declines in creatinine clearance on day 3 after the CER injection (Table 1). In addition, urinary excretions of protein and glucose were significantly higher in CER-administered rats compared with normal controls (Table 1).
Pathologic expression of CER in the rat kidney was verified with electron microscopy. However, electron micrographs showed a marked dilation of the vacuolar apparatus, swollen mitochondria, and loss of the microvillus border in the proximal tubules $24 \mathrm{~h}$ after CER exposure (Fig. 2B).

Effect of FTS Administration on the Levels of BUN and Plasma Creatinine in CER-Treated Rats In CER-treated rats, the effect of FTS was tested. Treatment with FTS $(50 \mu \mathrm{g} / \mathrm{kg}$, i.v.) 24 and $18 \mathrm{~h}$ before CER injection significantly decreased CER-induced increases in BUN levels (Table 1) and plasma creatinine levels (Table 1) $24 \mathrm{~h}$ after

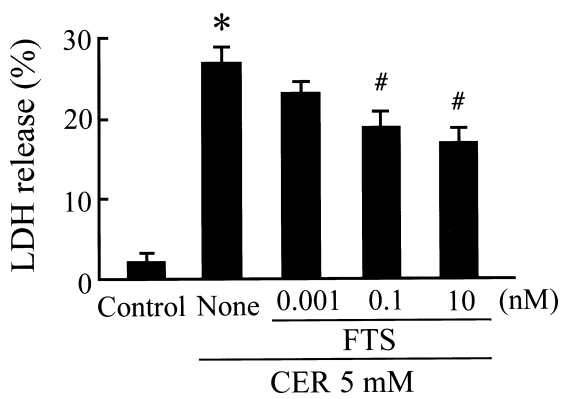

Fig. 1. Effect of Serum Thymic Factor, FTS, on Cephaloridine (CER)-Induced LLC-PK 1 Cell Injury

LLC-PK 1 cells were incubated in the medium with $5 \mathrm{~mm} \mathrm{CER} \mathrm{at} 37^{\circ} \mathrm{C}$ for $24 \mathrm{~h}$. Each value represents the mean \pm S.E.M. of three experiments. $* p<0.01$, compared with the control. ${ }^{*} p<0.05$, compared with 5 mM CER-treated group.

Table 1. Effects of Serum Thymic Factor, FTS ( $50 \mu \mathrm{g} / \mathrm{kg}$, i.v.), on Blood Urea Nitrogen (BUN), Plasma Creatinine, Creatinine Clearance, Urinary Excretion of Protein and Glucose in Rats Treated with Cephaloridine (CER, $1.2 \mathrm{~g} / \mathrm{kg}$, i.v.) for $24 \mathrm{~h}$

\begin{tabular}{|c|c|c|c|c|c|}
\hline Group & $\begin{array}{c}\text { BUN } \\
(\mathrm{mg} / \mathrm{dl})\end{array}$ & $\begin{array}{l}\text { Plasma creatinine } \\
(\mathrm{mg} / \mathrm{dl})\end{array}$ & $\begin{array}{l}\text { Creatinine clearance } \\
\qquad(\mathrm{ml} / \mathrm{h})\end{array}$ & $\begin{array}{l}\text { Excretion of protein } \\
\text { (mg/mg creatinine) }\end{array}$ & $\begin{array}{c}\text { Excretion of glucose } \\
\text { (mg/mg creatinine) }\end{array}$ \\
\hline Control $(n=6)$ & $18.1 \pm 1.9$ & $0.40 \pm 0.05$ & $97.5 \pm 10.2$ & $1.51 \pm 0.2$ & $0.80 \pm 0.05$ \\
\hline CER-treated $(n=6)$ & $56.8 \pm 3.1 * *$ & $1.27 \pm 0.13 * *$ & $32.1 \pm 3.80 *$ & $14.8 \pm 2.0 *$ & $45.1 \pm 3.90 *$ \\
\hline CER and FTS-treated $(n=6)$ & $34.5 \pm 4.1^{\# \#}$ & $0.88 \pm 0.03^{\# \#}$ & $77.0 \pm 8.93^{\#}$ & $8.12 \pm 0.8^{\#}$ & $5.01 \pm 1.80^{\#}$ \\
\hline FTS-treated $(n=6)$ & $17.5 \pm 2.0$ & $0.45 \pm 0.07$ & $83.5 \pm 11.1^{\#}$ & $1.43 \pm 0.5^{\#}$ & $0.75 \pm 0.02^{\#}$ \\
\hline
\end{tabular}

Each value represents the mean \pm S.E.M. $* p<0.01$, and $* * p<0.001$, compared with the control. \# $p<0.05$, and \# $p<0.01$, compared with CER-treated group.



Fig. 2. Electron Microscopic Findings of Renal Proximal Tubules in Control Rats (A), Cephaloridine (CER)-Injected Rats (B), Serum Thymic Factor (FTS)-Injected CER Rats (C), and FTS-Injected Control Rats (D)

The arrows inside photo B indicate, from left to right, vacuolar apparatus, the loss of the brush border, and swollen mitochondria. Scale bar, $10 \mu \mathrm{m}$. 
(A)

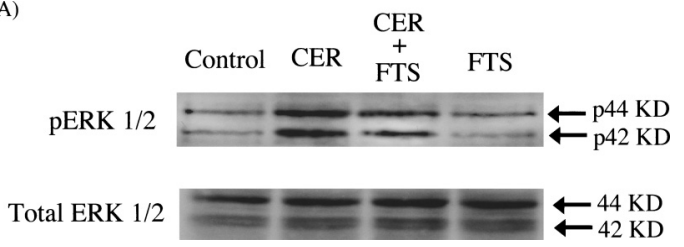

(B)

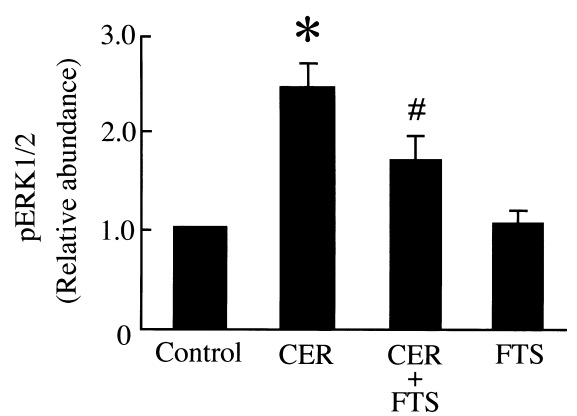

Fig. 3. Effect of Serum Thymic Factor (FTS) $(50 \mu \mathrm{g} / \mathrm{kg}$, i.v.), on Cephaloridine (CER)-Induced ERK Activation in the Nuclei Prepared from the Kidney Cortex of Rats Treated with CER for $24 \mathrm{~h}$

CER treatment increased ERK activation and FTS treatment suppressed the CER-induced ERK activation. The phosphorylated ERK (pERK) and total ERK bands were detected by Western blot analysis using each specific antibody against pERK1/2 and total ERK1/2 (A) and were quantitated by densitometric scanning (B). Blots are representative of three similar experiments. $* p<0.01$, compared with the control. ${ }^{*} p<0.01$, compared with CER-treated group.

CER injection. No significant differences in BUN and plasma creatinine levels were observed after the injection of FTS alone.

Effect of FTS on Renal Clearance of Creatinine and Urinary Excretion of Protein and Glucose in Rats Treated with CER The index at $24 \mathrm{~h}$ after CER injection showed significant elevations of protein and glucose levels in the CER-treated group compared with those in the salinetreated control group. Treatment of rats with FTS 24 and $18 \mathrm{~h}$ before CER injection attenuated the CER-induced decline of creatinine clearance (Table 1). FTS strongly prevented the increases in protein and glucose excretion induced by CER (Table 1). None of the changes were significantly different from those observed in rats given FTS alone. FTS also attenuated the CER-induced ultrastructural morphology changes indicative of renal dysfunction after CER treatment in rats (Fig. 2C). Treatment with FTS alone did not affect renal morphology (Fig. 2D).

Effect of FTS on CER-Induced ERK Phosphorylation in the Nuclei To investigate the effect of FTS on CER-induced ERK phosphorylation, nuclear fractions prepared from the kidney cortex of rats treated with CER were subjected to Western blotting with anti-phospho ERK and total ERK. The phosphorylation of ERK was clearly observed in nuclei prepared from the kidney cortex of rats $24 \mathrm{~h}$ after CER administration. FTS significantly suppressed the CER-induced increase in phosphorylated ERK in the nuclei (Fig. 3).

\section{DISCUSSION}

This study investigated the effect of FTS on CER-induced nephrotoxicity in rats. FTS is a multifunctional thymic hormone that regulates a variety of biological activities both in vivo and in vitro, including an immunobiological effect. ${ }^{10-15)}$
Some studies have reported that FTS prevents experimental pancreatitis and diabetes induced by alloxan or streptozotocin. $^{16,17)}$ Previous reports have also shown that FTS prevents bleomycin-induced pulmonary injury. ${ }^{33)}$ However, the exact mechanisms by which FTS protects against tissue injury are still unknown. FTS has also been demonstrated to increase superoxide disumutase (SOD) levels in senescenceaccelerated mice. ${ }^{32)}$ The physiological role of FTS in free radical-induced nephrotoxicity is poorly understood. It has been reported that ROS mediate CER-induced nephrotoxicity. $^{20-23,30,31)}$ In the present study, administration of FTS significantly attenuated CER-induced renal dysfunction in rats. Treatment with FTS in vitro significantly ameliorated CERinduced LLC-PK ${ }_{1}$ cell injury. From these data, it is clear that FTS, having a variety of biological activities, could modify cell damage and tissue injury, and possibly attenuate free radical-mediated renal cell injury and nephrotoxicity caused by CER.

In many kinds of cells, several studies have indicated that MAPK activation and ERK are involved in cell proliferation and survival. ${ }^{26,27)}$ However, previous studies from our laboratory demonstrate a crucial role of ERK activation in CER-induced renal cell injury. ${ }^{34)}$ The importance of ERK activation, which results in renal cell damage, is illustrated by the observation that $\mathrm{MEK}$ inhibitors ameliorate CER-induced renal cell injury and ERK activation in rat renal cortical slices. ${ }^{34)}$ Our present findings, considered together with those mentioned above, indicate the involvement of ERK activation in CER-induced nephrotoxicity. In the kidney, ERK activation is probably involved in the pathogenesis of acute renal failure. Consistent with this suggestion, Matsunaga et al. observed the involvement of ERK activation in zinc-related renal cell injury. ${ }^{37)}$ It has also been reported that an MEK inhibitor, U0126, effectively attenuates cisplatin-induced renal injury. ${ }^{38)}$ The most novel and striking finding of the present study is that intravenous administration of FTS results in suppressing CER-induced ERK activation. Our data demonstrated that protection from renal damage by FTS was associated with the suppression of ERK activation.

Zhao et al. demonstrated that FTS significantly enhanced the activity of Mn-SOD and Cu,Zn-SOD in the kidneys of senescence-accelerated mice (SAM-P/8). ${ }^{32)}$ It has also been reported that FTS decreased the contents of malondialdehyde (MDA), and can be used as an index of free radical generation in the kidney of SAM-P/8. Mn-SOD is located in the mitochondria, ${ }^{39)}$ while $\mathrm{Cu}, \mathrm{Zn}-\mathrm{SOD}$ is mainly in the cytosol and lysosomes. $^{40)}$ We previously suggested that mitochondrial generation of free radicals is associated with CER-derived nephrotoxicity in rats. ${ }^{31)}$ Previous studies have demonstrated that CER-induced renal cell injury is modified by phorbol 12-myristate 13-acetate (PMA), a PKC activator, in rat renal cortical slices. ${ }^{30)}$ We have also demonstrated that CER induces translocation of PKC $\delta$ into mitochondria and enhances mitochondrial generation of free radicals in the kidney cortex of rats, causing renal dysfunction. ${ }^{41)}$ ERK activation has been reported to be involved in the downstream PKC dependent pathway. ${ }^{42,43)}$ It is attractive to speculate that FTS has the beneficial role of modifying cell damage and tissue injury through suppressing the activations of PKC and ERK signaling pathways, possibly protecting against free radical-mediated nephrotoxicity caused by nephrotoxicants. 
In conclusion, this study demonstrated that CER-induced renal injury is mediated by the activation of the ERK signaling pathway, although further studies are required to characterize the exact mechanisms by which ERK activation causes renal dysfunction. Moreover, we demonstrated that FTS significantly ameliorated CER-induced renal damage and the phosphorylation of ERK in the kidney. These results suggest that FTS participates in protection from CER-mediated nephrotoxicity by suppressing the activation of the ERK signaling pathway induced by CER.

Acknowledgment This research was supported by a Grant-in-Aid for High Technology Research from the Ministry of Education, Culture, Sports, Science, and Technology, Japan.

\section{REFERENCES}

1) Atkinson R. M., Currie J. P., Davis B., Pratt D. A. H., Sharpe H. M., Tomic E. G., Toxicol. Appl. Pharmacol., 8, 398-406 (1966).

2) Foord R. D., J. Antimicrob. Chemother, 1 (Suppl.), 119-133 (1975).

3) Rush G. F., Heim R. A., Ponsler G. D., Engelhardt J., Toxicol. Pathol., 20, 155-168 (1992).

4) Braza M., J. Infect. Dis., 137, S60-S73 (1978).

5) Jung K. Y., Takeda M., Shimoda M., Narikawa S., Tojo A., Kim D. K., Chairoungdua A., Choi B. K., Kusuhara H., Sugiyama Y., Sekine T., Endou H., Life Sci., 70, 1861-1874 (2002).

6) Tunn B. M., Fernholt M., Schwartz A., J. Pharmacol. Exp. Ther., 191, $311-317$ (1974).

7) Wold J. S., Turnipseed S. A., Miller B. L., Toxicol. Appl. Pharmacol., 45, 115-122 (1979).

8) Tune B. M., Minor Electrolyte Metab., 20, 221-231 (1994).

9) Bach J. F., Dardenne M., Pleau J. M., Nature (London), 266, 55-56 (1977).

10) Kaufman D. B., Clin. Exp. Immunol, 39, $722-727$ (1980).

11) Bach J. F., Clin. Immunol. Allergy, 3, 133-156 (1983).

12) Bach M. A., Beaurain G., J. Immunol., 122, 1056-1058 (1979).

13) Bach J. F., Dardenne M., Pleau J. M., Bach M. A., Ann. N.Y. Acad. Sci., 249, 186-193 (1975).

14) Dardenne M., Nabama B., Lefancier P., Denien M., Choay J., Bach J. F., Proc. Natl. Acad. Sci. U.S.A., 79, 5370-5373 (1982).

15) Savino W., Dardenne M., Endocr. Rev., 21, $412-443$ (2000).

16) Mizutani M., EI-Fotoh M., Mori M., Ono K., Doi K., Awaya A., Matsumoto Y., Onodera T., Arch. Virol., 14, 73-83 (1996).

17) Yamanouchi T., Moromizato H., Kojima S., Shinohara T., Sekino N.,
Minoda S., Miyashita H., Akaoka I., Eur. J. Pharmacol., 25, 39-46 (1994).

18) Nagai Y., Osanai T., Sakakibara K., Jpn. J. Exp. Med., 52, 213-219 (1982).

19) Barbul A., Shawe T., Frankel H. L., Efron J. E., Wasserkrug H. L., Surgery, 106, 373-377 (1989).

20) Goldstein R. S., Pasino D. A., Hewitt W. R., Hook J. B., Toxicol. Appl. Pharmacol., 83, 261-270 (1986).

21) Rush G., Ponsle G., Toxicol. Appl. Pharmacol., 109, 314-326 (1991).

22) Kuo C. H., Maita K., Sleight S. D., Hook J. B., Toxicol. Appl. Pharmacol., 67, 78-88 (1983).

23) Cojocel C., Hannemann J., Baumann K., Biochim. Biophys. Acta, 834, 402-410 (1985).

24) Xial L., Pimentel D. R., Wang J., Sing K., Colucci W. S., Sawyer D. B., Am. J. Physiol. Cell Physiol., 282, C926-934 (2002).

25) Cobb M. H., Goldsmith E. J., J. Biol. Chem., 270, 14843-14846 (1995).

26) Boulton T. G., Nye S. H., Robbins D. J., Ip N. Y., Radziejewska E., Morgenbesser S. D., Depinho R. A., Paneyotatas N., Cobb M. H., Yancogenbesser G. D., Cell, 65, 663-675 (1991).

27) Davis R. J., J. Biol. Chem., 268, 14553-14556 (1993).

28) Campos-Gonzalez R., Kindy M. S., J. Neurochem., 59, 1955-1958 (1992).

29) Kindy M. S., J. Cereb. Blood Flow Metab., 13, 372-377 (1993).

30) Kohda Y., Gemba M., Jpn. J. Pharmacol., 85, 54-59 (2001).

31) Kohda Y., Gemba M., Biochem. Pharmacol., 64, 543-549 (2002).

32) Zhao X. H., Awaya A., Kobayashi H., Ohnuki T., Tokumitsu Y., Nomura Y., Jpn. J. Pharmacol., 53, 311-319 (1990).

33) Yara S., Kawakami K., Kudeken N., Tohyama K., Teruya K., Chinen T., Awaya A., Saito A., Clin. Exp. Immunol., 124, 77-85 (2001).

34) Kohda Y., Hiramatsu J., Gemba M., Toxicol. Lett., 143, 185-194 (2003).

35) Dignam J. D., Lebovitz R. M., Roeder R. G., Nucleic Acids Res., 11, 1475-1489 (1983).

36) Scheffe H., Biometika, 40, 87-104 (1953).

37) Matsunaga Y., Kawai Y., Kohda Y., Gemba M., J. Toxicol. Sci., 30, 135-144 (2005).

38) Jo S. K., Cho W. Y., Sung S. A., Kim H. K., Won N. H., Kidney Int., 67, 458-466 (2005).

39) Peeters-Joris C., Vandevoorde A. M., Baudhuin P., Biochem. J., 150, $31-39$ (1975).

40) Geller B. L., Winge D. R., J. Biol. Chem., 257, 8945-8952 (1982).

41) Kohda Y., Gemba M., J. Pharmacol. Sci., 98, 49-57 (2005).

42) Formisano P., Oriente F., Fiory F., Caruso M., Miele C., Maitan M. A., Andreozzi F., Vigliotta G., Condorelli G., Beguinot F., Mol. Cell. Biol., 20, 6323-6333 (2000).

43) Marais R., Light Y., Mason C., Paterson H., Olson M. F., Marshall C. J., Science, 280, 109-112 (1998). 